EPiC Series in Engineering
Volume 3, 2018, Pages 460-469
HIC 2018. 13th International
Conference on Hydroinformatics

\title{
Modelling rainwater harvesting and greywater reuse for tank size optimizations
}

\author{
Sara Simona Cipolla ${ }^{1}$ and Marco Maglionico ${ }^{2}$ \\ ${ }^{1}$ Interdepartmental Centre for Industrial Research- Building and Construction, University of \\ Bologna, Viale del Risorgimento 2, 40136 - Bologna, Italy \\ ${ }^{2}$ Department of Civil, Chemical, Environmental and Materials Engineering, University of \\ Bologna, Viale del Risorgimento 2, 40136 - Bologna, Italy. \\ sara.cipolla@unibo.it, marco.maglionico@unibo.it
}

\begin{abstract}
In the light of water shortages, frequently affecting many regions worldwide, domestic rainwater harvesting and greywater reuse systems represent an alternative source to provide non-potable water in buildings, reducing the water demand from mains water supply systems. This study fits this framework providing a methodology, based on a hydraulic/hydrological model developed by means of the EPA's Storm Water Management Model, which allow optimizing the system design by giving the opportunity to the user to consider different catchments surfaces (impervious, gravel and green roofs), plant's configurations, user's habits, water end-uses, and climate conditions. The model has used to model a residential building, located in the city of Bologna (Italy), and equipped with a hybrid greywater/rainwater system. Continuous simulations were performed with 13 years daily rainfall data, and the long-term performance of different system combinations were evaluated. The case study showed a non-potable water saving efficiency of $75.86 \%$, which accounts by $26.71 \%$ mains water withdrawal. The final goal of this paper is those of presenting the hydrological/hydraulic model that has been used as engine of a calculator tool for sizing and planning hybrid rainwater/greywater systems.
\end{abstract}

\section{Introduction}

Global population is facing with contrasting phenomena, on one hand climate change, which determines an increase in the frequency of drought and floods in many countries. On the other urban population growth, which already affects every continent and causes a growing demand for potable water and the increase in urban waterproof areas (Bitterman et al., 2016; Ward et al., 2012). Proper and sustainable management of these phenomena is both challenging in terms of water supply systems management and of urban drainage (Campisano et al., 2017; Casadio et al., 2013; Cipolla et al., 2016a). 
Harvesting and recycling less valuable water resources, such as rainwater or greywater, would reduce mains water withdrawal.

Rainwater harvesting systems (RWS) capture and store water locally; they are far from being considered new technologies, in fact, the first installations date back to thousands of years ago in many parts of the world (Mays, 2014). RWS could offer an important contribution to non-potable water supply, to urban flood protection, and to the reduction of costs for storm-water sewers. Furthermore RWSs, in particular when integrated with nature based solutions (green roofs, ponds, permeable pavements), have a positive impact on the local climate, reducing stormwater run-off, and then contributing to improve the urban environment (Gambi et al., 2011; Bonoli et al., 2013; Campisano et al., 2017; Cipolla et al., 2016a). A traditional rainwater harvesting system (RWS) comprises four basic elements: a collection area, several gutters and downspouts, a tank, and a pump system. RWSs are based on a relatively clean natural resource, which can be stored safely for long periods. The amount of water harvested varies depending on rainfall intensity, household size, roof size and type, and average dry weather period between rainfall events. Consequently, the water saving efficiency can range from less than 1\% up to 100\% (Domínguez et al., 2017; Ghisi and Mengotti de Oliveira, 2007).

Several technical standards provide guidance and recommendations on the design, installation, testing and maintenance of rainwater harvesting systems supplying non-potable water to urban dwellings (e.g. the DIN 1989-1:2002 in Germany, the BS 8515:2009+A1:2013 in UK, the Manual on rainwater Harvesting in Texas (Texas Water Development Board, 2005), the Rainwater Harvesting and Use Research Report (ABCB, 2016) in Australia, the UNI/TS 11445 in Italy, etc.). As the tank is the most expensive element of the system, all the standards provide methods to determine its optimum storage capacity.

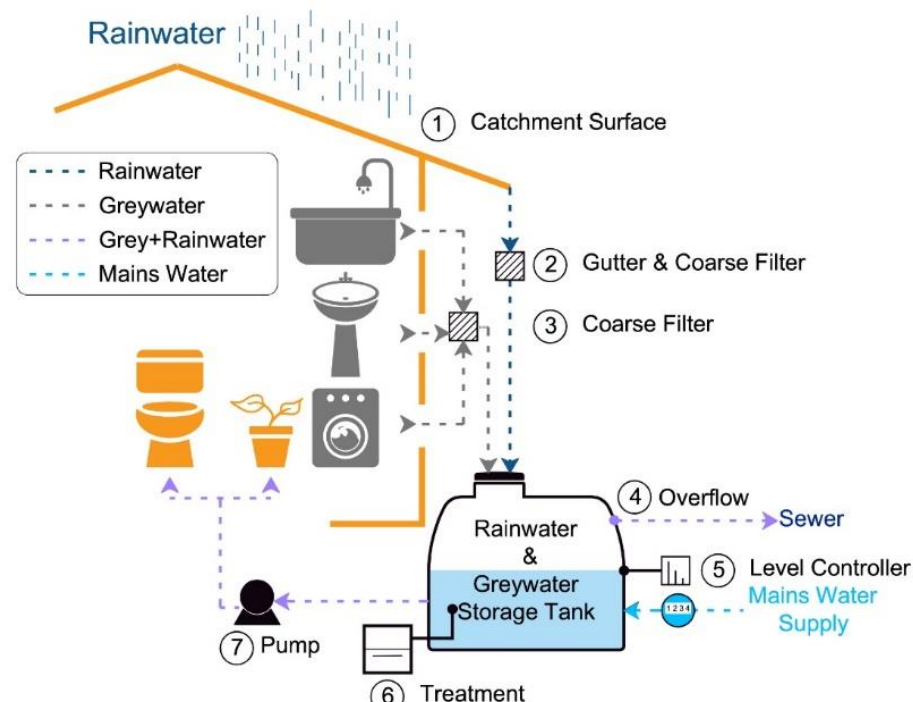

Figure 1: Hybrid rainwater-greywater systems

At the building scale, another on-site source of water is the treated greywater. It makes up the largest proportion of the total wastewater flow from homes (water discharged from washing machines, showers, tubs, and bathroom sinks), and it has a very low nutrient content; moreover, it is generated regardless of climate conditions. In terms of daily production, the scientific literature indicates that the 
greywater volumes can represent from the $50 \%$ to the $80 \%$ of the total in-house water demand (Domínguez et al., 2017), those values are similar to those found in Italy, during the monitoring activities carried out within the AQUASAVE project (LIFE 97 ENV/IT/000106). This project showed that the average water consumption of potable water in a residential building, equipped with low consumption devices, is about $106.35 \mathrm{l} / \mathrm{p} / \mathrm{d}$ of which $23 \%$ is used for toilet flushing; $12 \%$ for dishwashers and washing machines, $4 \%$ for food preparation, and $28 \%$ for other uses (Failla et al., 2001).

Technical Standards that provide guidance and recommendations on the design, treatment, installation, testing and maintenance of greywater recovery systems are less common (e.g. BS 85251:2010, BS 8525-2:2011). The "Guidelines for the safe use of wastewater, excreta and greywater", published by the World Health Organization (WHO) in 2006, constitutes the key reference for any country wishing to manage health risks associated with water reuse, and to develop a policy framework aiming to minimize such risks. In Italy, although many municipalities encourage the installation of greywater recycling systems, there are no technical standards capable of providing guidance to engineers or local authorities for either designing or verification. As greywater systems become more and more popular, there is a need for standardization of designing, installation and maintenance. Moreover, since the plants for the onsite reuse of greywater are coupled with systems for the onsite reuse of rainwater (Fig. 1), giving rise to the so-called "hybrid rainwater-greywater systems" (Leong et al., 2017a), the regulatory gap of the former influences the latter.

This manuscript focuses precisely on this last category of installations because they offer both the benefits of rainwater and greywater systems. Hybrid systems manage rainwater locally (Kim and Yoo, 2009) mitigating urban flooding (Palla et al., 2017), reducing the volume and concentration of the pollution of wastewater spilled into the receiving waters through Combined Sewer Overflows (Casadio et al., 2010; Penn et al., 2013). Furthermore, hybrid systems are generally less sensitive than greywater systems to the variation in the number of inhabitants, and less sensitive than rainwater systems to climate changes. In fact, the continuous supply of greywater makes it possible to compensate for the seasonal variation in rainfall reducing the payback time of the system (Leong et al., 2017b). Considering all these aspects, it is evident that the achievement of all these benefits is connected to the correct design of the overall system.

This paper presents a numerical hydrological/hydraulic model, developed by means of EPA's SWMM (Storm Water Management Model), which can be used by both engineers and local authorities to determine the optimal capacity of the storage tank in a hybrid system. Furthermore, the model will allow to quantify both stormwater and wastewater volumes reduction discharged into the sewer system. To support the investigation, the model has been applied to an existing building located in the city of Bologna (Italy).

\section{Materials and methods}

\subsection{Hydrological/hydraulic modelling}

The hydraulic/hydrological model has been undertaken by means of EPA SWMM software, version 5.1.012 (Rossman and Huber, 2016), as done by other authors (see Palla et al. (2011) for an overview). A subcathment, a pipe, two pumps, a weir, a node, two storage units, and two outfalls compose the model, which ensures the representation and simulation of a hybrid rainwater-greywater system (HRGWS). Greywater has been modelled as a positive constant daily inflow to the tank, while the nonpotable water demand, to meet toilet flushing and garden watering supply, has been modelled as a negative inflow to the tank, and a pump system respectively. Water can continue to enter into the tank, raising the water level until it reached the overflow pipe, at that level the water will be discharged into 
the sewer system though the overflow (weir). A SWMM rule controls the water level within the tank; it allows water to enter from the main water supply when the water level drops below a minimum required level (replenishment water control). The outputs from this model are the predicted yield and the overflow over the simulation period as a function of the system setup (roof characteristics, rainwater demand, and tank storage volume). Continuous simulations are performed over 12-years at 1-day time interval; as for the initial condition, the tank is assumed empty as generally recommended (Palla et al. 2017).

\subsection{Performance analysis}

Two indexes, evaluated with respect of the entire simulation period, provide the performances of different system configurations. The first is the water-saving efficiency, $E$, in which the difference between the non-potable water supply (rainwater + greywater) $Y_{t}\left[\mathrm{~m}^{3}\right]$ and the replenishment water $R_{t}$ $\left[\mathrm{m}^{3}\right]$ are compared with the non-potable demand (e.g. toilet flushing and irrigation) $D_{t}\left[\mathrm{~m}^{3}\right]$ both in each time step $t$, and $T$ is the total number of time steps in the period of simulation (adapted from Andrade et al. (2017).

$$
E=\frac{\sum_{t=1}^{T}\left(Y_{t}-R_{t}\right)}{\sum_{t=1}^{T} D_{t}}
$$

The second index is the watewater overflow ratio, $O$, in which the non-potable water, exceeding the tank capacity, $O_{t}\left[\mathrm{~m}^{3}\right]$ is compared with system inflow (rainwater + greywater) $Q_{t}\left[\mathrm{~m}^{3}\right]$.

$$
O=\frac{\sum_{t=1}^{T} o_{t}}{\sum_{t=1}^{T} Q_{t}}
$$

\begin{tabular}{lcr}
\hline Variable & Value & System Unit \\
\hline City & Bologna (Italy) & {$[-]$} \\
System Type & HRGWS & {$[-]$} \\
Equivalent Inhabitants & 66 & {$[\mathrm{p}]$} \\
Area of the roof - impervious & 400 & {$\left[\mathrm{~m}^{2}\right]$} \\
Area of the roof - green roof & - & {$\left[\mathrm{m}^{2}\right]$} \\
Area of the roof - gravel roof & - & {$\left[\mathrm{m}^{2}\right]$} \\
Area of the garden & 892 & {$\left[\mathrm{~m}^{2}\right]$} \\
Total daily water supply & 105 & {$[1 / \mathrm{p} / \mathrm{d}]$} \\
Greywater production $(42 \%$ of the total supply) & 44.1 & {$[1 / \mathrm{p} / \mathrm{d}]$} \\
Non-potable water supply for WC (26\% of the total supply) & 27.4 & {$[1 / \mathrm{p} / \mathrm{d}]$} \\
Non-potable water supply for irrigation & 4 & {$\left[1 / \mathrm{m}^{2} / \mathrm{d}\right]$} \\
Irrigation month & Apr.-Sept. & {$[-]$} \\
\hline
\end{tabular}

Table 1: Characteristics of the building

\subsection{Case study analysis}

The case study is an apartment building built in 2014 and located in the western suburbs of the city of Bologna (Italy). It consists of seven floors, and it includes 22 apartments of different sizes. The building has a garden of $892 \mathrm{~m}^{2}$ of which the $87 \%$ is private while the remaining is a shared garden. 
The building, built in 2014, is equipped with water-saving devices and a HRGWS for collecting and recovering rainwater and greywater, with a tank storage capacity of $16 \mathrm{~m}^{3}$.

Simulations were performed using daily rainfall and air temperature data for a 13-year period, i.e., $1^{\text {st }}$ January $2004-31^{\text {st }}$ December 2016 . Data were sourced from the historical daily climate records provided by the Regional Agency for Prevention, Environment and Energy (ARPAE, 2016). Furthermore, cold, hot and recycled water consumptions were measured from 18 January 2014 to 19 February 2016 four flats of the same building. During the monitoring period, two apartments were not inhabited, but the owner irrigated their gardens with non-potable water when were for sale. A family (4 $\mathrm{AE})$ and a single person $(1 \mathrm{AE})$ inhabited the others. The main characteristics of the building and the parameters used in this study are shown in table 1.

\begin{tabular}{lcccr}
\hline Flat code & $\mathrm{A} 1$ & $\mathrm{~A} 2$ & $\mathrm{~A} 3$ & $\mathrm{~A} 4$ \\
\hline Size $\left[\mathrm{m}^{2}\right]$ & 51 & 103 & 85 & 92 \\
Garden size $\left[\mathrm{m}^{2}\right]$ & - & 243 & 257 & 281 \\
$\begin{array}{l}\text { Plumbing } \\
\text { fixture }\end{array}$ & low-consumption & low-consumption & low-consumption & low-consumption \\
Inhabitants & 1 adult & $\begin{array}{c}\text { 2 adults and } 3 \\
\text { children }\end{array}$ & - & - \\
\hline
\end{tabular}

\section{Results and discussion}

\subsection{Monitoring activity}

Cold water, hot water, and non-potable water consumption were measured for each apartment (Tab. 2). Flat $\mathrm{A} 1$ is a one bedroom flat of $51 \mathrm{~m}^{2}$ located on the third floor of the building, with no garden. It has been inhabited by a female person (40 years old) since April 01/04/2015. Recycled water is used only for toilet flushing. Fig. 2a shows the cold, hot and non-potable water consumption during the monitoring activity (354 days).
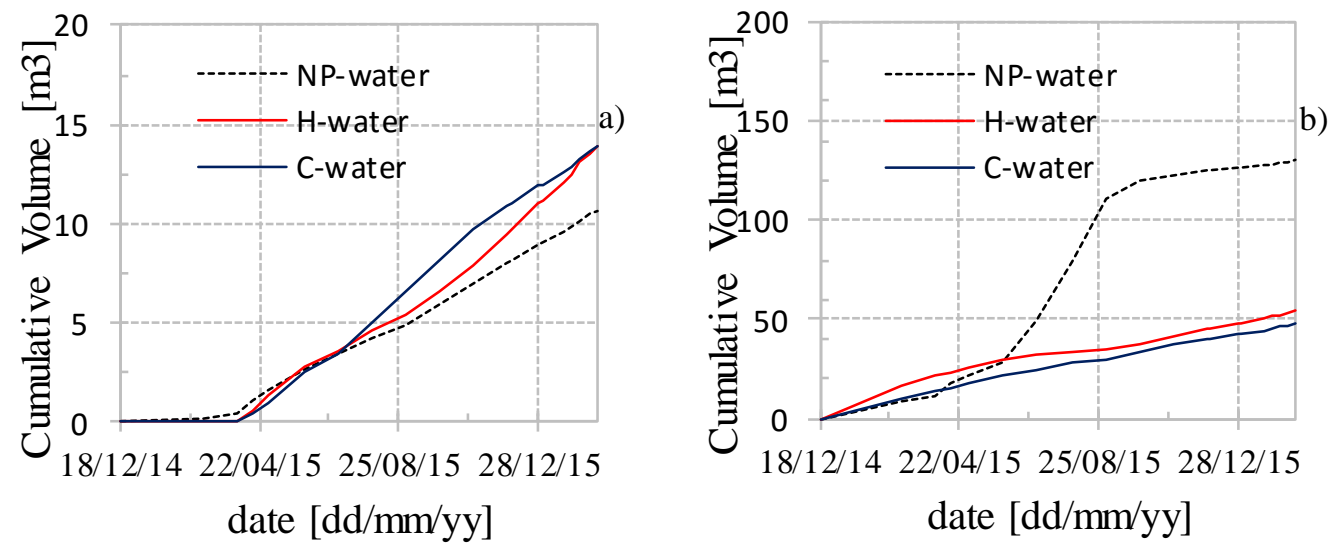

Figure 2: Hot, cold and non-potable water consumption for flat A1 (a) and A2 (b) 
The total daily consumption is $108.76 \mathrm{l} / \mathrm{p} / \mathrm{d}$, of which $72.26 \%$ is potable water subdivided in hot $(36.0 \%$ or $39.43 \mathrm{l} / \mathrm{p} / \mathrm{d})$ and cold $(36.26 \%$ or $39.1 \mathrm{l} / \mathrm{p} / \mathrm{d})$ water. The remaining $27.2 \%(30.17 \mathrm{l} / \mathrm{p} / \mathrm{d})$ is non potable water used for toilet flushing. Non-potable water consumption remains constant throughout the year, while in summer there is a reduction in the consumption of hot water in favour of the cold, and vice-versa in winter.

\begin{tabular}{lccccccc}
\hline Date & Rainfall & $\begin{array}{c}\text { Temp. } \\
\max \end{array}$ & $\begin{array}{c}\text { Temp. } \\
\text { min }\end{array}$ & $\begin{array}{c}\text { WC } \\
\text { flushing } \\
1 / \mathrm{p} / \mathrm{d}\end{array}$ & $\begin{array}{c}\text { Irrigation } \\
{\left[1 / \mathrm{m}^{2} / \mathrm{d}\right]}\end{array}$ & $\begin{array}{c}\mathrm{A} 3 \\
\text { Irrigation } \\
{\left[1 / \mathrm{m}^{2} / \mathrm{d}\right]}\end{array}$ & $\begin{array}{c}\mathrm{A} 4 \\
\text { Irrigation } \\
{\left[1 / \mathrm{m}^{2} / \mathrm{d}\right]}\end{array}$ \\
\hline jan-15 & 7.8 & 17.2 & 1.3 & 30.74 & - & - & - \\
feb-15 & 197.2 & 14 & 1.8 & 30.74 & - & - & - \\
mar-15 & 122.4 & 23.4 & 7 & 21.50 & - & - & 2.4 \\
apr-15 & 110.0 & 26.6 & 7.8 & $\mathbf{2 1 . 4 4}$ & $\mathbf{1 . 3 9}$ & 2.6 & 0.5 \\
may-15 & 67.6 & 29.1 & 12.8 & $\mathbf{2 1 . 4 4}$ & $\mathbf{0 . 9 4}$ & 1.8 & 2.0 \\
jun-15 & 98.2 & 32.8 & 19.3 & $\mathbf{2 1 . 4 4}$ & $\mathbf{2 . 8 6}$ & 3.5 & 3.8 \\
jul-15 & 2.6 & 37.5 & 22 & $\mathbf{2 1 . 4 4}$ & $\mathbf{3 . 9 6}$ & 4.7 & 3.2 \\
aug-15 & 107.0 & 35.9 & 20.9 & $\mathbf{2 1 . 4 4}$ & $\mathbf{4 . 0 6}$ & 5.2 & 4.5 \\
sep-15 & 13.6 & 34.1 & 14.7 & $\mathbf{2 1 . 4 4}$ & $\mathbf{1 . 4 2}$ & 6.0 & 8.0 \\
oct-15 & 117.2 & 25.2 & 10.9 & 19.60 & - & - & - \\
nov-15 & 62.8 & 21.9 & 3.8 & 17.08 & - & - & - \\
dic-15 & 0.0 & 13.5 & 3 & 13.71 & - & - & - \\
jan-16 & 28.4 & 18.4 & 0.6 & 17.28 & - & - & - \\
feb-16 & 166.6 & 16.2 & 5.7 & 20.83 & - & - & - \\
\hline
\end{tabular}

Table 3: Total monthly rainfall, maximum and minimum average monthly air temperature and non-potable water consumption for the flat A2, A3 and A4
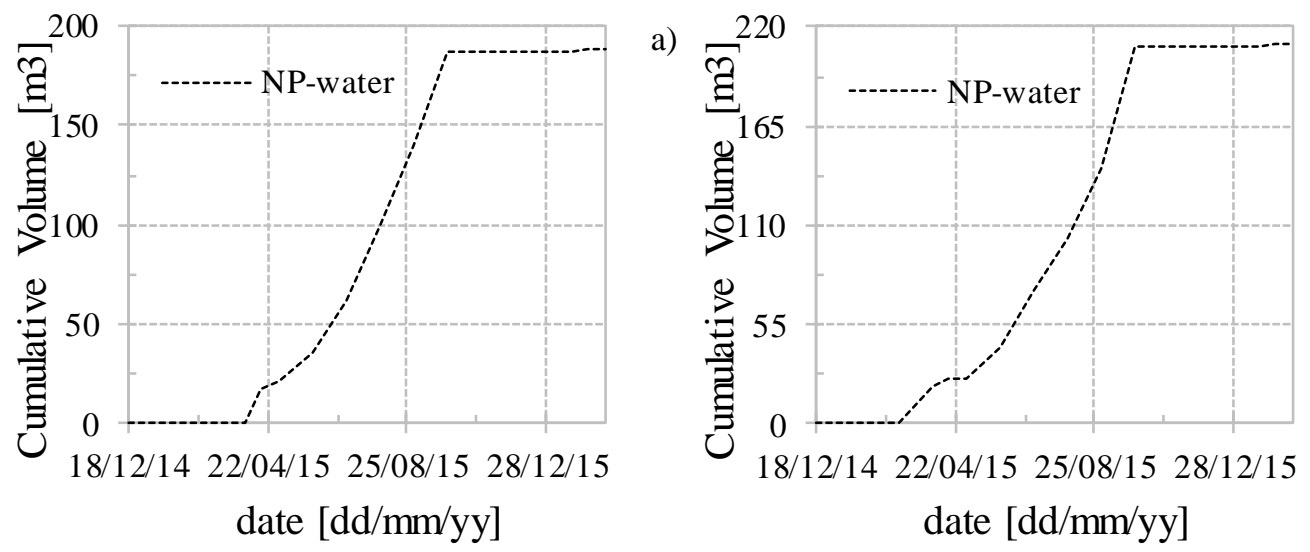

b)

Figure 3: Non-potable water consumption for flat A3 (a) and A4 (b)

Flat A2 is a $103 \mathrm{~m}^{2}$ flat located on the ground floor. It consists of a living room, a kitchen, a double bedroom, two single bedrooms and two bathrooms, one with the shower and the other with a bathtub. 
The house has a private garden of $243 \mathrm{~m}^{2}$. The apartment has been inhabited since 18 December 2014 by a family of 5 people including a new-born and two children. Non-potable water is used for toilet flushing and summer irrigation of the garden. Fig. $2 \mathrm{~b}$ shows the cold, hot and non-potable water consumption during the monitoring activity (428 days). By considering four equivalent inhabitants, the average hot and cold water consumption results in $31.15 \mathrm{l} / \mathrm{p} / \mathrm{d}$ and $28.06 \mathrm{l} / \mathrm{p} / \mathrm{d}$ respectively. The consumption of hot water is higher than that of cold water during the entire monitoring period and both consumption shows a constant trend. The consumption of non-drinking water shows a completely different trend from that of apartment A1. This variation is due to the presence of the garden that is irrigated during the summer. The monitoring data measures the consumption of drinking water on an aggregate basis (toilet flushing + irrigation). The irrigation period started in April 2015 and ended in September. To estimate the volumes of non-drinking water used for irrigation purposes, the average volume consumed for toilet flushing during the non-irrigated months was estimated and subtracted from the measured data. Dividing the monthly irrigation volumes thus obtained, for garden's area to be irrigated, the average daily water consumption for irrigation purposes was obtained in the various months (Tab. 3). Based on these considerations, the non-potable water consumption for toilet flushing was estimated to be equal to about $21.44 \mathrm{l} / \mathrm{p} / \mathrm{d}$, while the irrigation volume ranges between 0.94 and $4.061 / \mathrm{m}^{2} / \mathrm{d}$. Moreover, there is no direct correlation between the monthly precipitation and the irrigation volumes. Flat A3 and flat A4 are an 85 and a $92 \mathrm{~m}^{2}$ flats located on the ground floor. Both apartments have a garden of 257 and $281 \mathrm{~m}^{2}$ respectively. During the monitoring period, the apartments were for sale, but the building's owner irrigated the lawn. This allows measuring the volumes of non-potable water, used exclusively for irrigation purposes (Fig. 3a and Fig. 3b).

Table 3 shows the average monthly consumption of non-drinking water for gardening for flats A3 and A4. It ranges from a minimum value of $0.51 / \mathrm{m}^{2} / \mathrm{d}\left(\mathrm{A} 4\right.$, March 2015) to a maximum of $8.0 \mathrm{l} / \mathrm{m}^{2} / \mathrm{d}$ (A4, August 2015), with an average value of 4.0 and $3.51 / \mathrm{m}^{2} / \mathrm{d}$ for flats A3 and A4 respectively. The values measured in these apartments are slightly higher than the one measured in the apartment inhabited by the family.

The monitoring campaign allowed measuring hot, cold and recycled water consumption for 2 flats (A1 and A2), and the recycled water used for garden watering for the others two flats (A3 and A4). The results obtained are comparable with those published by Failla et al. (2001) and related to the Italian context. Due to the reduced number of measured data (low number of families, short monitoring period, etc), they were not used for modelling, but to support the choice of using results already published by other authors.

\subsection{Simulation results}

The model has been used to simulate the hydrologic/hydraulic behavior of the hybrid system present in the building under twelve-year daily rainfall precipitation (2005-2016). The average annual precipitation recorded is $781.33 \mathrm{~mm}, 2010$ with 1060.44 and 2011 with $464.21 \mathrm{~mm}$ of rain, respectively, are the rainiest and the driest year.

Simulations results show that the existing hybrid system has an average annual efficiency of $75.86 \%$, while the wastewater overflow undergoes a significant reduction as demonstrated by the overflow performance indicator equal to $26.71 \%$. The model allows simulating different operating scenarios. For example, if the plant was powered only by greywater, the efficiency would be reduced to a value equal to $67.15 \%$. On the other hand, if the plant was powered only by rainwater, the efficiency would drop to $20.82 \%$ drastically. This is caused by the strong variability of rainfall, both in terms of intensity and of average dry weather time between two consecutive rainfall events. The model was then used to evaluate how a progressive change in the storage volume influenced the performance indices of the system. These variations were made considering all the possible operating scenarios (hybrid, rainwater, and greywater). Fig. 4a shows an example of model output, it summarizes the results concerning water saving obtained from the use of non-potable water for toilet flushing and irrigation 
for different tanks storage fractions. The general trend of the curves highlights a non-linear increase of $E$ as the storage fraction increases for RWSs, while the trend is linear in the case of GWSs and HRGWS. The three curves are flat despite the value of tank volume increases, revealing reduced marginal water saving benefits as the tank size grows. These finding suggests that the RWS is not convenient. In fact, the high demand for non-drinking water for gardens irrigation and for toilets flushing is not compatible with the small collection surface present in the building. These results agree with the findings of Palla et al. (2011), which demonstrated that if the ratio between the demand for non-drinking water and the inflow is higher than the value of two, the efficiency varies in the 0.2-0.4 range almost irrespective of the storage volume. On the contrary, greywater represent an almost constant daily inflow to the system and the hybrid system or a HRGWS show efficiencies over $65 \%$ even with modest volume tanks. As expected rainwater systems, $O$ decreases as tank volume increases, while in HRGWSs and GWSs the reduction is approximately $30 \%$ and $20 \%$ regardless of tank size (Fig. 4 b).

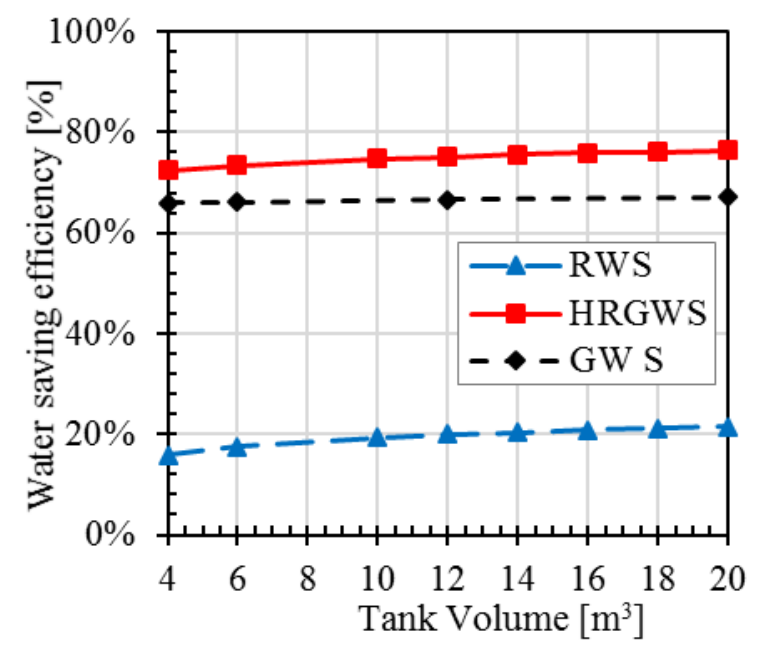

a)

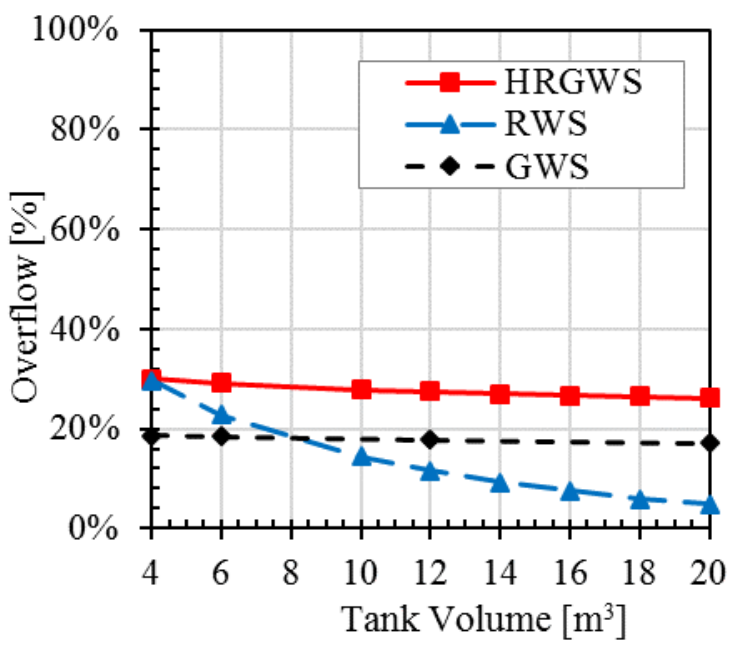

b)

Figure 4: Water saving-(a) and overflow (b) for different values of tank storage volume and system configuration. 


\section{Conclusion}

The present study analyzes the long-term behavior of a building equipped with a hybrid rainwatergreywater systems plant. A long-term hydraulic/hydrological numerical model realized with the SWMM software has been used to evaluate different system configuration. To support the choice of the water end-use consumptions and of the greywater production, that were set up into the model, the water consumption (cold, hot, and recycled water) of four flats, located into the case study building, have been analyzed. Data, collected by the facility manager of the building for billing purposes, although they are not extremely accurate and referred to only four residential units, provide several useful information. Measured data were found to be compatible with those shown in more detailed studies (Failla et al., 2001), validating the choice to use those literature data for modelling purposes.

The performances of different systems configurations have been estimated by using 13 years of real daily rainfall data as input. The model shows that the real system configuration has a water saving efficiency of $75.86 \%$, and that the volumes of wastewater (greywater + rainwater discharged into the combined sewer systems), are reduced by $73.29 \%$. Model has then been used to estimate both $\mathrm{E}$ and $\mathrm{O}$ for nine different tank volumes. Simulations revealed a marginal water saving benefits as the tank size grows, which is mainly attributable to the general characteristics of the building (small size of the roof, high number of inhabitants, and large extent of irrigated gardens). Despite this, the hybrid system, compared to a rainwater harvesting system or a greywater systems, seems to be the most efficient because it is able to supply the highest water.

\section{References}

ABCB, (2016), Rainwater Harvesting and Use-research Report, Australian Building Codes Board on behalf of the Commonwealth of Australia and States and Territories of Australia. Andrade, L.R., Maia, A.G., Lucio, P.S., (2017), Relevance of hydrological variables in water-saving efficiency of domestic rainwater tanks: Multivariate statistical analysis. J. Hydrol. 545, 163-171.

Andrade LR, Maia AG, Lucio PS. (2017), Relevance of hydrological variables in water-saving efficiency of domestic rainwater tanks: Multivariate statistical analysis. J Hydrol; 545:163-71.

Antonopoulou, G., Kirkou, A., Stasinakis, A.S., (2013). Quantitative and qualitative greywater characterization in Greek households and investigation of their treatment using physicochemical methods. Sci. Total Environ. 454-455, 426-432.

ARPAE, (2016). URL http://www.arpae.it/dettaglio_generale.asp?id=3284\&idlivello=1625

Bitterman, P., Tate, E., Van Meter, K.J., Basu, N.B., (2016). Water security and rainwater harvesting: A conceptual framework and candidate indicators. Appl. Geogr. 76, 75-84.

Bonoli, A., Conte, A., Maglionico, M., Stojkov, I., (2013). Green roofs for sustainable water management in urban areas. Env. Eng. and Man. J., 12, S11, Supplement, 153-156.

Campisano, A., Butler, D., Ward, S., Burns, M.J., Friedler, E., DeBusk, K., Fisher-Jeffes, L.N., Ghisi, E., Rahman, A., Furumai, H., Han, M., (2017). Urban rainwater harvesting systems: Research, implementation and future perspectives. Water Res. 115, 195-209. doi:10.1016/j.watres.2017.02.056

Casadio, A., Maglionico, M., Bolognesi, A., Artina, S., (2010). Toxicity and pollutant impact analysis in an urban river due to combined sewer overflows loads. Water Sci Technol., 61(1), 207-215.

Casadio, A., Cipolla, S.S., Maglionico, M., Martinini, P., (2013). Numerical modelling of the sewer system of Rimini : CSOs reduction on the Adriatic Sea. Env. Eng. and Man. J., 12, S11, Supplement, 121-124.

Cipolla, S.S., Maglionico, M., Stojkov, I., (2016a). Experimental Infiltration Tests on Existing Permeable Pavement Surfaces. Clean - Soil, Air, Water, 44, 89-95. 
Cipolla, S.S., Maglionico, M., Stojkov, I., (2016b). A long-term hydrological modelling of an extensive green roof by means of SWMM. Ecol. Eng. 95, 876-887.

Development, B.T.W., (2005). The Texas Manual on Rainwater Harvesting. Texas Water Dev. Board 1,88 .

Domínguez, I., Ward, S., Mendoza, J.G., Rincón, C.I., Oviedo-Ocaña, E.R., (2017). End-user costbenefit prioritization for selecting rainwater harvesting and greywater reuse in social housing. Water, 9, 516.

Gambi, G., Maglionico, M., Tondelli, S., (2011). Water management in local development plans: The case of the old fruit and vegetable market in Bologna. Procedia Eng. 21, 1110-1117.

Ghisi, E., Mengotti de Oliveira, S., (2007) . Potential for potable water savings by combining the use of rainwater and greywater in houses in southern Brazil. Build. Environ. 42, 1731-1742.

Failla B, Spadoni M, Stante LD, Cimatti E, Bortone G., (2001) The Aquasave Project : an innovative water saving system in a residential building, Italy. Integr Water Resour Manag 121-5.

Kim, K., Yoo, C., (2009). Hydrological Modeling and Evaluation of Rainwater Harvesting Facilities: Case Study on Several Rainwater Harvesting Facilities in Korea. J. Hydrol. Eng. 14, 545-561.

Leong, J.Y.C., Chong, M.N., Poh, P.E., Vieritz, A., Talei, A., Chow, M.F., (2017a). Quantification of mains water savings from decentralised rainwater, greywater, and hybrid rainwater-greywater systems in tropical climatic conditions. J. Clean. Prod. 176, 946-958.

Leong, J.Y.C., Oh, K.S., Poh, P.E., Chong, M.N., (2017b). Prospects of hybrid rainwater-greywater decentralised system for water recycling and reuse: A review. J. Clean. Prod. 142, 3014-3027.

Mays L.W., (2014). Use of cisterns during antiquity in the Mediterranean region for water resources sustainability. Water Sci. Technol. Water Supply 14, 38-47.

Palla, A., Gnecco, I., La Barbera, P., (2017). The impact of domestic rainwater harvesting systems in storm water runoff mitigation at the urban block scale. J. Environ. Manage. 191, 297-305. doi:10.1016/j.jenvman.2017.01.025

Palla, A., Gnecco, I., Lanza, L.G., (2011). Non-dimensional design parameters and performance assessment of rainwater harvesting systems. J. Hydrol. 401, 65-76.

Penn, R., Schütze, M., Friedler, E., (2013). Modelling the effects of on-site greywater reuse and low flush toilets on municipal sewer systems. J. Environ. Manage. 114, 72-83.

Rossman, L.A., (2015). Storm Water Management Model User's Manual.

Rossman, L., Huber, W.C., (2016). Storm Water Management Model Reference Manual Volume I Hydrology I.

Ward, S., Barr, S., Butler, D., Memon, F.A., (2012). Rainwater harvesting in the UK: Socio-technical theory and practice. Technol. Forecast. Soc. Change 79, 1354-1361. 